\title{
Gastroesophageal Junction
}

National Cancer Institute

\section{Source}

National Cancer Institute. Gastroesophageal Junction. NCI Thesaurus. Code C32668.

The anatomical location where the esophagus joins to the stomach. 